\title{
AcademyHealth Update
}

AcademyHealth (www.academyhealth.org) is the professional home for health services researchers, policy analysts, and practitioners, and a leading, non-partisan resource for the best in health research and policy. AcademyHealth promotes the use of objective research and analysis to inform health policy and practice.

\section{Conference to Feature Nation's Critical Health Policy Issues}

Hear from top Bush administration officials, health advisors to the 2004 presidential candidates, political pollsters and commentators, and many more experts at the National Health Policy Conference, January 28 - 30 in Washington, D.C. Join more than 700 colleagues for a first look at the 2004 health policy agenda. The conference features critical topics such as Medicare and prescription drugs, the uninsured, public health system preparedness, obesity, and non-visit-based communication. View an up-to-date agenda and register online at www.academyhealth.org/nhpc.

\section{Call for Abstracts: Deadline January 15}

A Call for Abstracts has been issued for AcademyHealth's 2004 Annual Research Meeting (ARM), June $6-8$ in San Diego. Submit your abstract, poster, or panel online at www.academyhealth.org/arm/abstracts by January $15,2004$.

This year's themes include Behavioral Health, Child Health, Chronic Care Delivery, Coverage \& Access, Disparities, Health Insurance Markets, International, Long Term Care, Management \& Organization, Medicare \& Prescription Drugs, Public Health, Quality \& Patient Safety, Technology, Innovation \& Evaluation, and Workforce.

Join old and new friends to discuss cutting-edge research, debate current health policy issues, and sharpen research skills. Visit www.academyhealth.org/arm for news on the meeting.

\section{Cyber Seminars Series Continues in 2004}

AcademyHealth's easily accessible two-hour, Web- and audio-based Seminars allow you or groups of individuals to learn the latest health services 
research methods from the experts for a low fee, without the cost of hotel or travel. All Cyber Seminars are from 1:00 - 3:00 p.m. ET.

- Wednesday, January 21

The Healthcare Cost and Utilization Project (HCUP): Data and Tools to Support Health Services Research (Faculty: Claudia Steiner and Carol Stocks, both from $A H R Q$ )

- Thursday, February 26

What is GIS and How Can it Be Used Effectively in Health Services Research? (Faculty: Tom Ricketts, University of North Carolina, Chapel Hill )

- Tuesday, March 23

Measuring the Benefits Side of the Value Equation: Assessing Technical Quality in the Health System (Faculty: Beth McGlynn, RAND Health)

- Tuesday, April 20

MEPS: The Fundamentals (Faculty: Nancy Krauss and Mamatha Pancholi, both from $A H R Q$ )

Visit www.academyhealth.org/cyberseminars/ live to register.

\section{Nominate Your Colleagues!}

AcademyHealth seeks to recognize individuals who have made an impact on the field of health services research. Nominations for 2004 are due by Monday, March 1, and will be presented at the ARM in June in the following categories:

- Distinguished Investigator Award

- Alice S. Hersh New Investigator Award

- Article-of-the-Year Award

- Dissertation Award

Learn more at www.academyhealth.org/awards.

\section{New Initiative to Increase Diversity among Health Services Researchers}

AcademyHealth has received a grant from the W.K. Kellogg Foundation to explore how to increase diversity in the field of health services by examining various procedures of 15 randomly selected health services research programs at both public and private institutions. A report detailing best practices, lessons 
learned, and unmet needs will be published and widely disseminated in the fall of 2004. For more details, contact Virginia Van Horne at virginia.vanhorne @academyhealth.org.

\section{Research Training Directory Goes International}

AcademyHealth hosts an online directory of global health services research and health policy training programs. Averaging close to 3,330 visitors to the site per month, 142 programs from around the world are currently profiled. The directory provides key information about post-baccalaureate certificate, master's, doctoral, and postdoctoral programs in the fields of health services research and health policy. To learn more, visit www.academyhealth.org/ directory. 
